\title{
Action-Oriented Benchmarking: Using the CEUS Database to Benchmark Commercial Buildings in California
}

Paul Mathew \& Evan Mills, Lawrence Berkeley National Laboratory

Norman Bourassa \& Martha Brook, California Energy Commission

\begin{abstract}
$\underline{\text { ABSTRACT }}$
The 2006 Commercial End Use Survey (CEUS) database developed by the California Energy Commission is a far richer source of energy end-use data for non-residential buildings than has previously been available and opens the possibility of creating new and more powerful energy benchmarking processes and tools. In this article - Part 2 of a two-part series - we describe the methodology and selected results from an action-oriented benchmarking approach using the new CEUS database. This approach goes beyond whole-building energy benchmarking to more advanced end-use and component-level benchmarking that enables users to identify and prioritize specific energy efficiency opportunities - an improvement on benchmarking tools typically in use today.
\end{abstract}

\section{Introduction}

Action-oriented benchmarking extends generalized whole-building energy benchmarking to include analysis of system and component energy use metrics and features. If coupled with the appropriate decision-tree logic, it thereby allows users to identify, screen and prioritize potential efficiency opportunities, which in turn can be used to inform and optimize a full-scale audit or commissioning process (see figure 1 in companion article [Mills et al. 2007]).

Action-oriented benchmarking extends traditional whole-building benchmarking in three important ways:

- $\quad$ End use benchmarking - which shows the energy intensities and savings opportunities within each end use and its priority relative to other end uses.

- Features benchmarking i.e. identifying the efficiency characteristics of specific systems, components, and operational conditions.

- Correlating features with end-use energy intensities, which can help assess the approximate savings potential from specific actions.

The CEUS database offers a rich source of data for action-oriented benchmarking - with energy use data and building characteristics for almost 2800 buildings representing a cross section of commercial buildings in California.

In this article, we first provide an overview of the CEUS database. Next, we illustrate the use of CEUS for action-oriented benchmarking (using offices and schools as examples). We conclude with some observations about the limitations and outlook for this type of analysis.

\section{Overview of CEUS database}

The Commercial End Use Survey (CEUS) database was developed by the California Energy Commission (CEC) to support demand forecasting. For more detailed information on CEUS, see Ramirez et al. [2005] and the CEUS final report [Itron 2006]. Some of the key characteristics are summarized below: 
- It involved a survey of about 2800 commercial buildings in four utility districts (PG\&E, SCE, SDGE, SMUD) and seven major climate zones within California.

- The survey covered 12 major building types and 62 sub-types.

- The buildings were selected by modified stratified random sampling using four frames: building type, utility district, climate zone, and load. In selected cases, buildings were switched to allow for buildings that had interval metered data.

- A standardized survey tool was used to document over 100 physical and operational characteristics of the building. Energy use was obtained from utility bills.

- DOE-2 simulation models were developed for each building, based on the survey data. Simulation models were calibrated with monthly utility data. Additionally, short term metering and/or interval metering were used for calibration in a subset $(\sim 31 \%)$ of buildings. Calibration was to within $5 \%$ on annual energy use and $10 \%$ on monthly energy use [Ramirez 2007].

The CEUS survey represents the most comprehensive survey of this type ever done on commercial buildings at this scale. Nevertheless, it is important to recognize some important limitations:

- While the survey form was very detailed (elaborate enough to develop of simulation models), there are gaps in data collection, as in any large survey.

- As noted earlier, the energy use and peak electric demand data in CEUS are from calibrated simulations.

- It is not truly representative of the entire state of California, because some utility districts are not covered.

These limitations notwithstanding, the CEUS database is still a remarkably rich source of data, and offers a unique opportunity for developing action-oriented benchmarking methods applicable to a wide range of commercial building types.

\section{Using CEUS for action-oriented benchmarking}

\subsection{End-use energy benchmarking}

End-use energy benchmarking shows the overall potential for reductions in energy intensity within each end use and its priority relative to other end uses. The Carbon Trust in the UK [Action Energy 2003] has demonstrated the application of end-use benchmarking to identify efficiency opportunities in office buildings in the United Kingdom. Figure 1 shows the range of energy intensities for various end-uses in large office buildings in the CEUS data set. All end-uses show a wide range. Lighting has the highest median value, followed by cooling, office equipment, and ventilation. Users can plot their building's end use to identify and prioritize which end uses offer the greatest opportunity for savings. An additional way to analyze this is to compare the average end-use break out to that of the user's building. Figure 2 shows the average end-use breakout for schools in various California climate zones. 




Figure 1 End use energy intensities for large office buildings in California. Source energy for electricity counted at $10.28 \mathrm{kBTU} / \mathrm{kWh}$

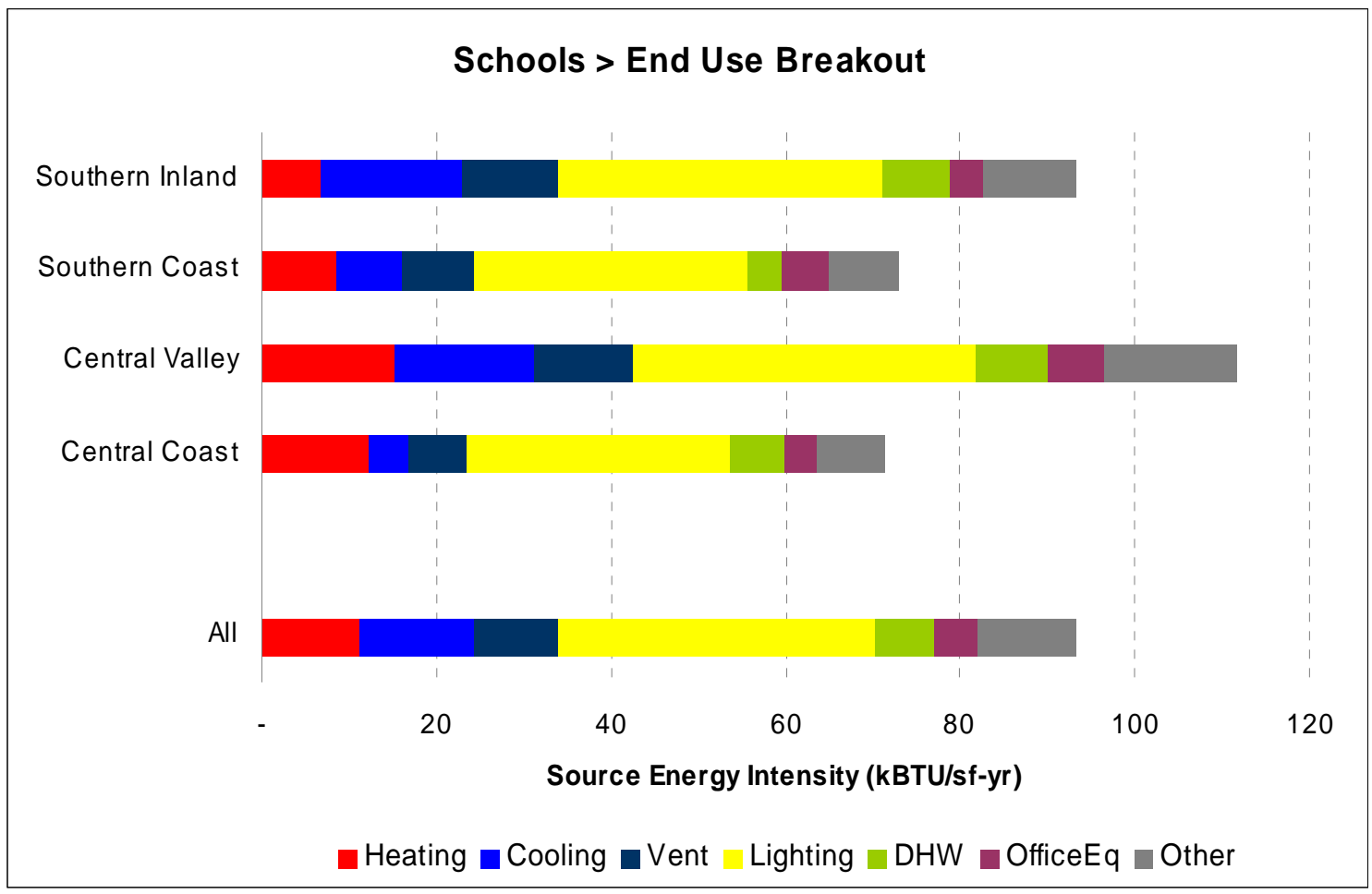

Figure 2 Average end use breakouts for schools in various California climate zones. 


\subsection{Features benchmarking}

The CEUS survey was remarkably detailed in documenting building features and operational characteristics (Figure 3 shows an illustrative selection).

\begin{tabular}{|c|c|}
\hline \multirow[t]{4}{*}{ Lighting } & Lamp \\
\hline & Ballast \\
\hline & Control \\
\hline & Hours of use \\
\hline \multirow[t]{5}{*}{ Envelope } & Roof insulation \\
\hline & Wall insulation \\
\hline & Glazing type \\
\hline & Exterior shading \\
\hline & Interior shading \\
\hline \multirow[t]{14}{*}{ Air Handlers } & System type \\
\hline & Age \\
\hline & Hours \\
\hline & Temp Control \\
\hline & Optimal start/stop \\
\hline & Economizer \\
\hline & Supply Fan Motor Eff \\
\hline & Supply Airflow Efficiency \\
\hline & Cooling Type \\
\hline & Cooling EER/SEER \\
\hline & Heating Type \\
\hline & Heating fuel \\
\hline & Heating efficiency \\
\hline & HP Soft Start \\
\hline
\end{tabular}

\begin{tabular}{|l|l|}
\hline \multirow{5}{*}{ Chillers } & Type \\
\cline { 2 - 2 } & Fuel type \\
\cline { 2 - 2 } & Heat rejection type \\
\hline & Age \\
\hline & Efficiency \\
\hline & Chilled Water Reset \\
\hline & VSD compressor \\
\cline { 2 - 2 } & Cooling Lockout \\
\cline { 2 - 2 } Water side economizer \\
\hline \multirow{5}{*}{ Chilled Water Pumps } & Age \\
\hline & Motor type \\
\hline & Motor efficiency \\
\hline & Type \\
\hline & Temp control \\
\hline & Age \\
\hline & Fan type \\
\hline & Fan control \\
\hline & Fan motor eff \\
\hline & Pump type \\
\hline & Pump motor eff \\
\hline
\end{tabular}

Figure 3. A selection of features documented in the CEUS database

Statistical distributions of these features allow users to "benchmark" the presence or absence of energy efficiency features in their building, relative to the prevalence of these features in the peer dataset. For example, Figure 4 shows the prevalence of different types of temperature controls for schools and large office buildings. While energy management systems (EMS) are very dominant in large office buildings, there is a wider range system types in schools, with only about $24 \%$ having EMS.
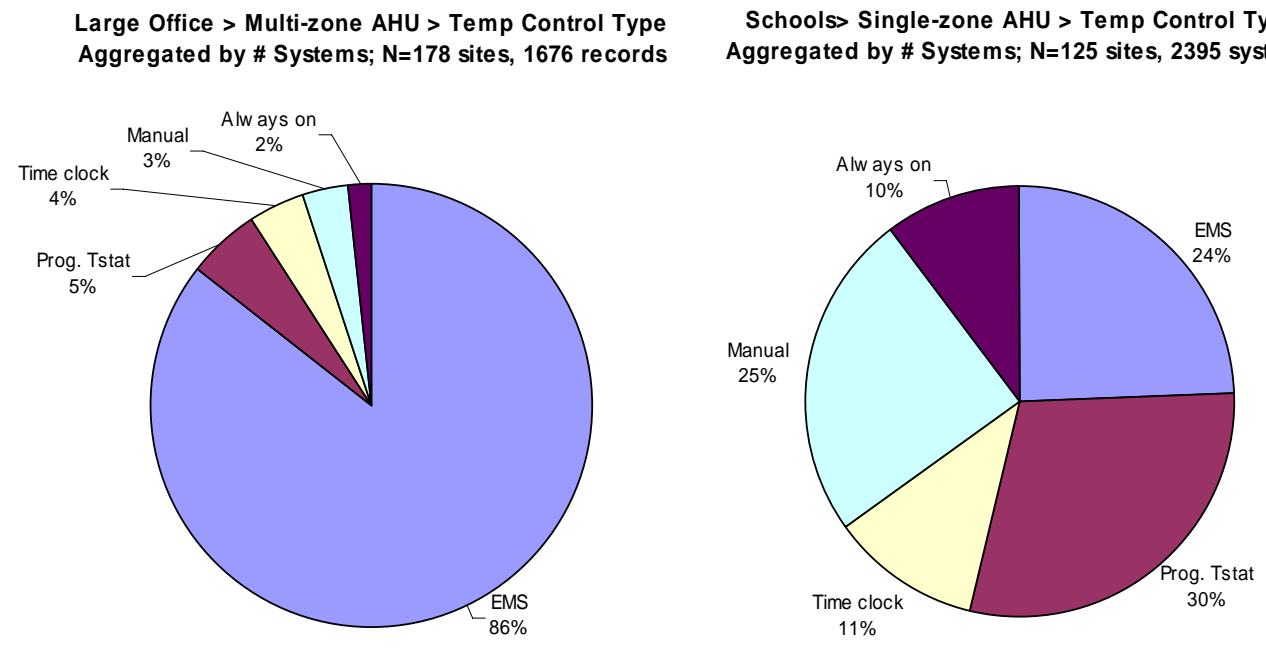

Figure 4 Prevalence of different types of temperature controls for schools and large office buildings 
Component and system efficiencies such as HVAC power density [Kavanaugh et al. 2006] are another form of features-based benchmarking. Figure 5 shows the range of fan efficiency for various types of multi-zone air handlers in large office buildings. Note that although there is a wide range (factor of two) within each type, the medians for each type are very similar.



Figure 5. Range of fan system efficiencies for various types of multi-zone air handlers in large office buildings.

\subsection{Correlation between features and end use energy intensities}

Correlating building features with end use energy intensities can, in principle, provide an indication of potential savings from different types of energy-efficiency improvements. However, it is important to note at the outset that there are two key limiting factors for this type of analysis:

- End-use energy intensity is not equivalent to energy efficiency, and is invariably a function of multiple features with interrelated impacts on energy use. Therefore, it is difficult to isolate the impact of a single feature - and the absence of a correlation does not necessarily imply that the feature has no impact.

- $\quad$ End use energy intensities are only available at the building level, whereas a feature may not be uniform across a given building. For example, there may be different types of lighting fixtures or different types of HVAC systems within a given building. Therefore correlating a given feature to an end use energy signature may be feasible only where in cases where the feature is largely uniform across the building.

These caveats notwithstanding, such correlation analyses can provide useful information for the action-oriented benchmarking process. For example, Figure 6 shows the correlation between lighting energy intensity and two lighting features: lamp power density and lighting control type. As expected, lighting energy intensity is positively correlated with lamp power density. The chart also shows that the linear regression lines for the three control types largely overlap. However, there is a much wider scatter for manually controlled systems than for the other two control types. (Note that even with automated controls, lights are left on when not needed because of false triggering and the delay effect. Therefore, in buildings where occupants are conscientious about turning off lights, manual controls may be more effective than automated controls.) 


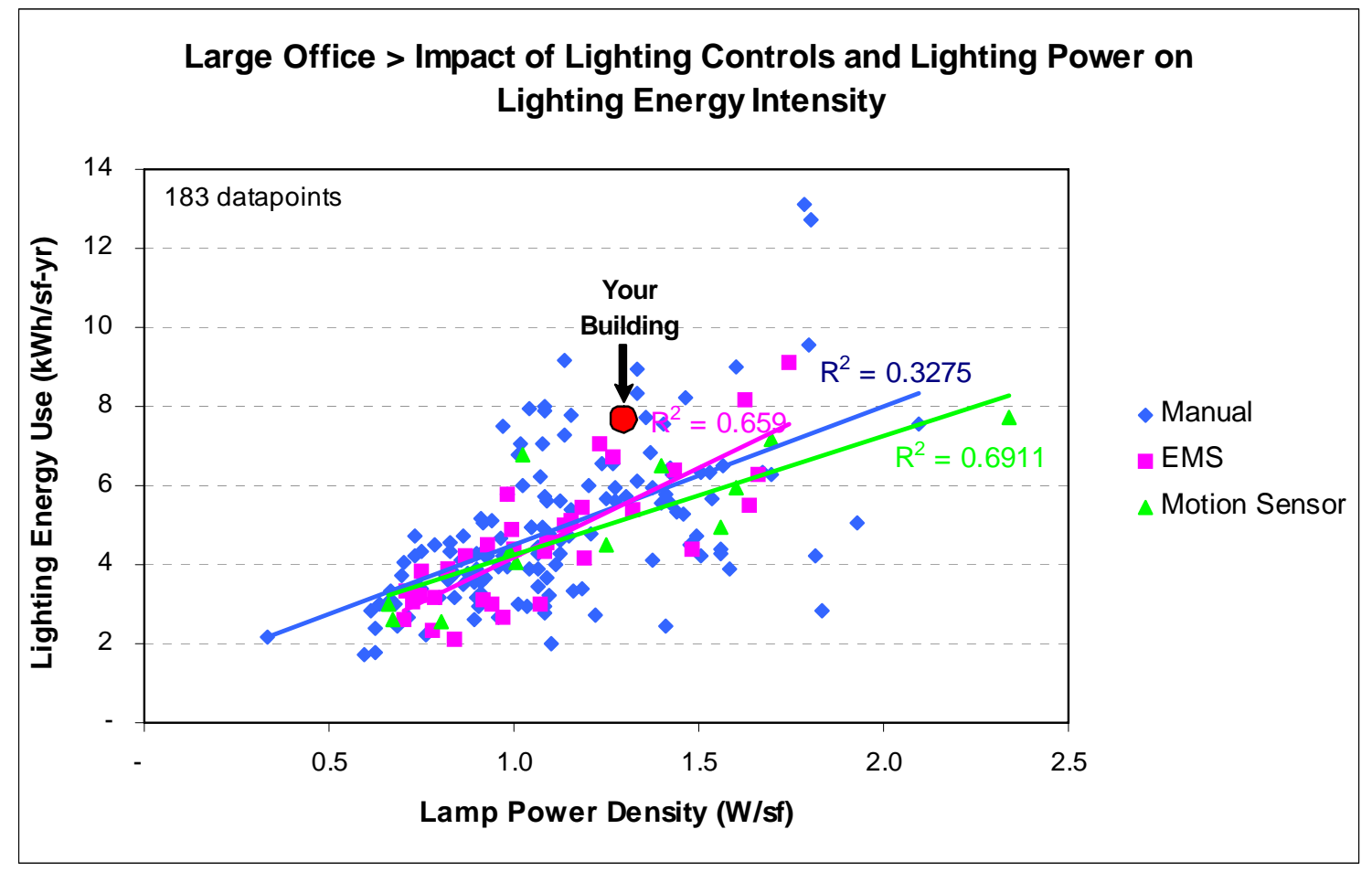

Figure 6 Correlation between lighting energy intensity and lamp power density for various control types in large office buildings. Includes only buildings where one control type predominates (>95\% of lighting $k W$ )

As another example, Figure 7 shows the correlation between ventilation energy intensity and HVAC system type in large office buildings. As expected, the median intensity for buildings with VAV systems is lower than the medians for buildings with multi-zone and constant volume systems. But here again, there is a wide range for each system type - reinforcing findings from other studies [e.g. Johnson 2002] that the presence of energy efficient features in and of itself does not guarantee a low energy building, and that building commissioning and operation are critical to ensuring achieving low energy intensity. The variance of median and minimum values between the three system types in Figure 7 also shows that features-based peer groups can help improve the relevance and meaning of action-oriented benchmarking. 


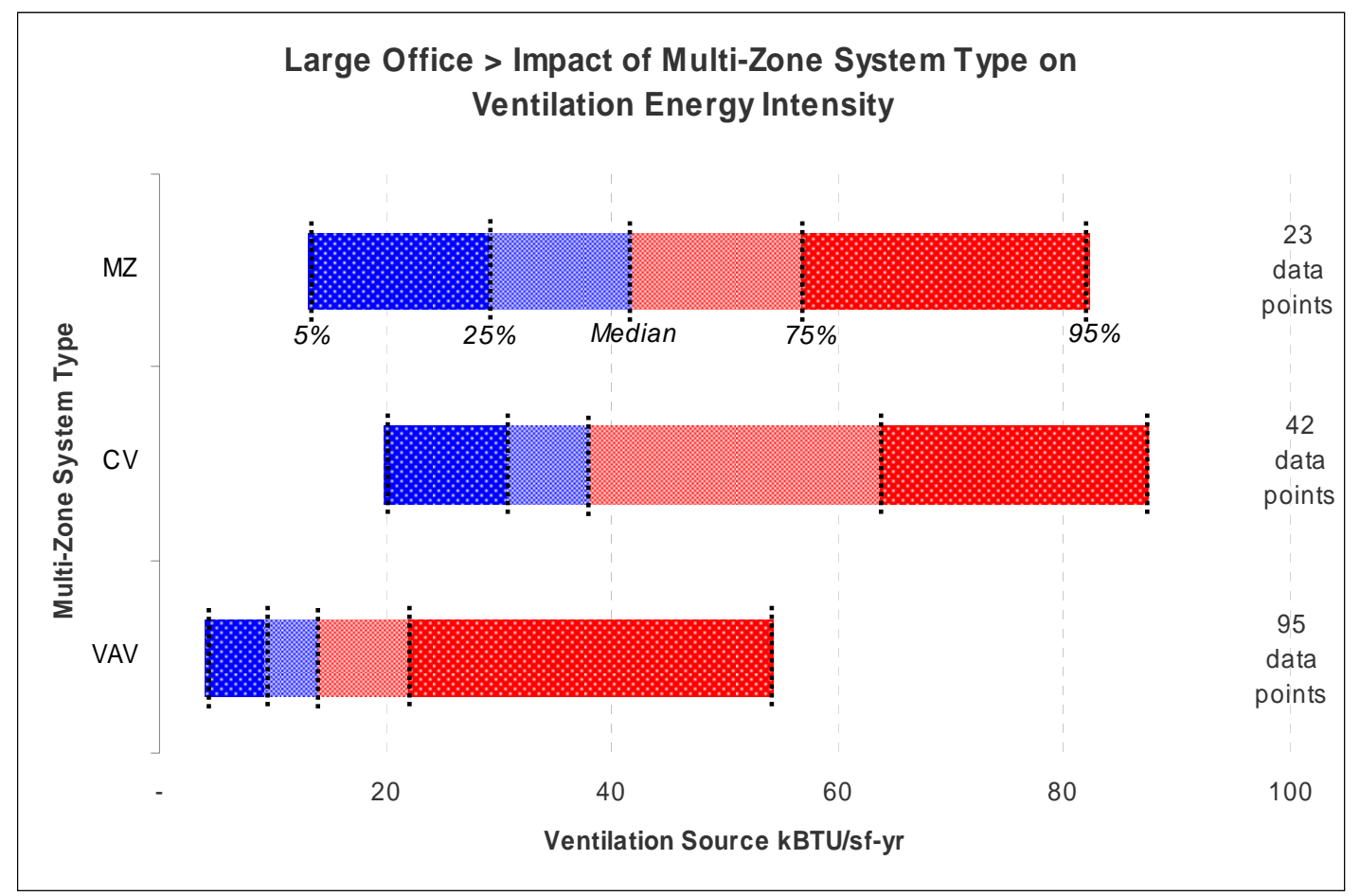

Figure 7 Correlation between ventilation energy intensity and various HVAC system types in large office buildings. Includes only buildings where one system type predominates (>95\% of units)

\subsection{Providing guidance on potential actions}

Collectively, the three types of benchmarking analyses discussed above can be used to provide guidance on actions to reduce the energy use. Of course, such guidance cannot be specific enough to substitute for a full energy audit. Rather, the approach used here is to work from a predefined list of actions, and then assess the relevance and impact of each of these actions for the given building using benchmarking-level data:

- "Relevance" in this context simply indicates how likely the action is to be applicable to the building being benchmarked. It is largely determined by the presence or absence of a feature. For example, the relevance of the action "Install EMS lighting controls" would be relevant if the building currently has only manual controls.

- "Impact" indicates the effect of this action in reducing overall energy use. Note that an action with high relevance may not necessarily have high impact. For example, in a laboratory building with standard fluorescent lamps, switching to energy efficient lamps may have a high relevance, but a low impact because lighting is a small percentage of total energy use.

The degree of specificity in assessing relevance and impact for each action is a function of the depth and detail of the database and availability of data for the individual building being benchmarked. In the EnergyIQ tool and its underlying web-based Action-Oriented Benchmarking system (described in the companion article [Mills et al. 2007]), both relevance and impact are rated in qualitative terms (e.g. high, medium, low). Figure 8 provides illustrative examples of the criteria for determining the relevance and impact of selected actions in EnergyIQ, using applicable metrics and features. Additionally, the tool will indicate the typical cost-effectiveness of each action i.e. based on current practice, but not specifically for the given building. 


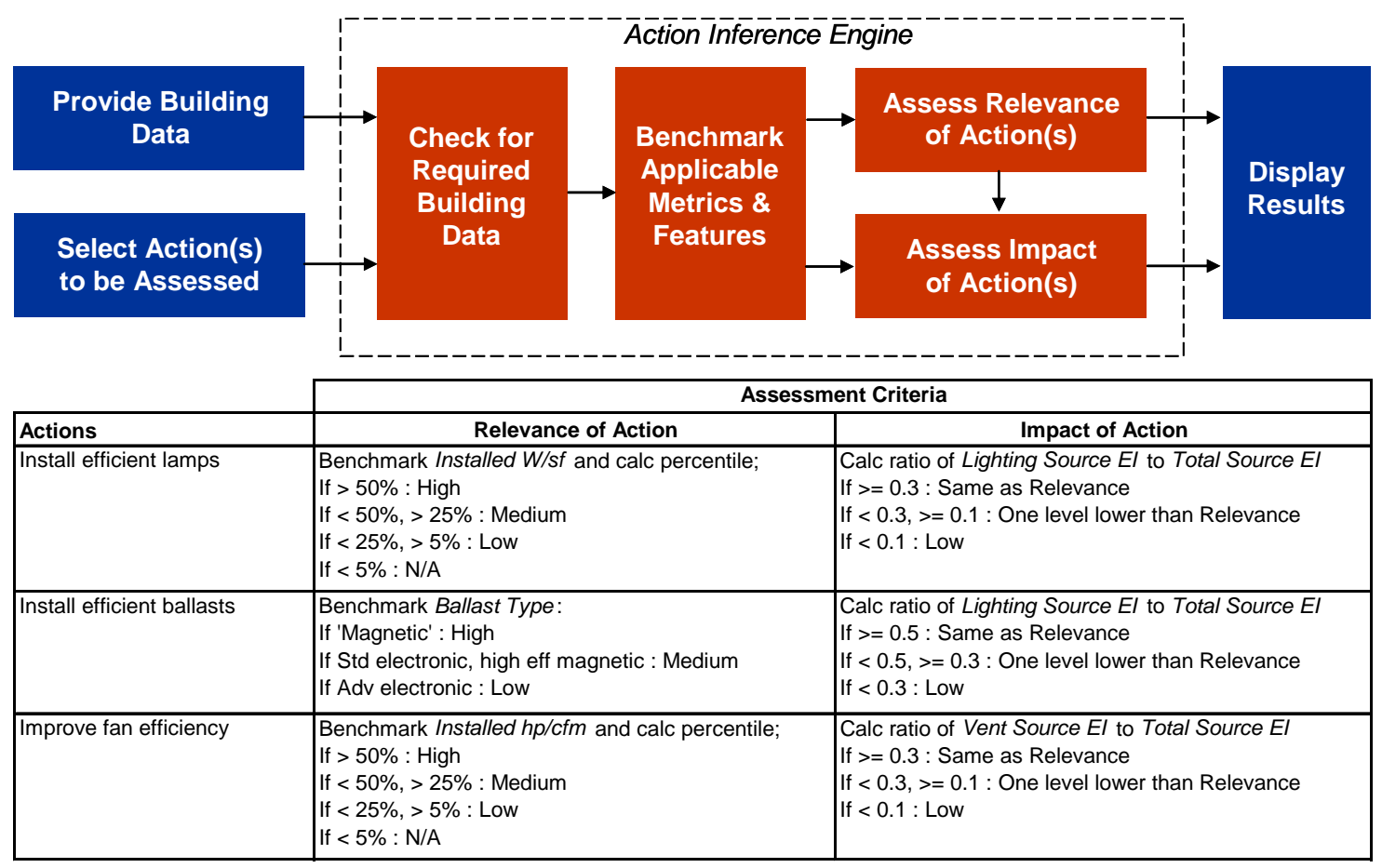

Figure 8. Conceptual illustration of action inference mechanism (top), with illustrative examples of how benchmarking metrics and features are used to qualitatively rate ("high-medium-low") the relevance and impact of energy efficiency actions in EnergyIQ.

\section{Conclusion and Outlook}

This article provided illustrative examples of "action-oriented" benchmarking using the CEUS database. Specifically, building owners and managers can benchmark various end-uses as well as system and component features, which in turn makes it possible to identify and assess the potential for various actions. However, it is also important to note that action-oriented benchmarking is not an "audit in a box." It cannot provide the level of specificity and depth of an on-site audit. Rather, it can improve significantly on first-generation benchmarking to help identify opportunities and prioritize potential actions for more detailed assessment. Additionally, it can be used to improve building operations by incorporating the metrics and benchmarks into the continuous commissioning process.

From a policy perspective, the effectiveness and widespread application of action-oriented benchmarking is contingent the availability of reliable end-use data for buildings, availability of information rich databases such as CEUS, and development of tools and user interfaces that adequately facilitate access to the benchmarking process and development of recommended actions. Currently, end-use metering is still relatively rare, and no other states have databases like CEUS. However, the growing momentum for voluntary and mandatory benchmarking in buildings may motivate a positive change on both these fronts. 


\section{References}

Action Energy 2003. Energy Consumption Guide 19 ("ECON 19"), Energy Use in Offices. http://www.carbontrust.co.uk/publications

Johnson, J. 2002. "Is What They Want What They Get? Examining Field Evidence for Links Between Design Intent and As-Built Energy," Proceedings, 2002 ACEEE Summer Study on Energy Efficiency In Buildings. American Council for an Energy Efficient Economy.

Kavanaugh, S. P., S. E. Lambert, N. Devin. 2006. "HVAC Power Density: An Alternate Path to Efficiency,” ASHRAE Journal. Vol. 48. No. 12.

Mills, E., P. Mathew, N. Bourassa, M. Brook. 2007. "Action-Oriented Benchmarking: Concepts and Tools." Lawrence Berkeley National Laboratory Report (in preparation).

Itron. 2006. California End Use Survey. Prepared for the California Energy Commission, Report CEC-400-2006-005. http://www.energy.ca.gov/2006publications/CEC-400-2006-005/CEC-4002006-005.PDF

Ramirez, R., F. Sebold, T. Mayer, M. Ciminelli, M. Abrishami. 2005. "A Building Simulation Palooza: The California CEUS Project and DrCEUS." Building Simulation 2005. Ninth International Conference. International Building Performance Simulation Association. pp. 10031010 .

Ramirez, R. 2007. Personal communication regarding calibration of CEUS simulation models.

\section{Acknowledgment}

The work described in this article was sponsored by the California Energy Commission's Public Interest Energy Research (PIER) program and by the Assistant Secretary of Energy Efficiency and Renewable Energy, Building Technologies Program, of the U.S. Department of Energy under Contract No. DE-AC02-05CH11231.

\section{$7 \quad$ Author Biographies}

Paul Mathew is a Staff Scientist at Lawrence Berkeley National Laboratory. His current work is focused on energy efficiency and green design for laboratories and other high-tech buildings, as well as energy benchmarking tools and techniques. In addition to technical research and consulting, he also teaches courses on energy efficient design. Prior to joining LBNL, he worked at Enron Energy Services, and the Center for Building Performance at Carnegie Mellon University. He has a Bachelor's degree in Architecture, and a Ph.D. in Building Performance and Diagnostics. Email: pamathew@lbl.gov; Phone: (510) 486-5116.

Evan Mills is a Staff Scientist at Lawrence Berkeley National Laboratory. He has worked on energy and environmental systems analysis since the early 1980s--from local to global scales. He has a Masters of Science degree from the Energy and Resources Group at UC Berkeley and a Ph.D. from the Department of Environmental and Energy Systems Studies at the University of Lund in Sweden. He has published over 200 technical articles and reports and has contributed to nine books. He is a member of the Intergovernmental Panel on Climate Change (IPCC), which shared the 2007 Nobel Peace Prize with former U.S. Vice President Albert Gore. His work in energy efficiency includes energy benchmarking, residential energy simulation, risk-assessment of energy-efficient technologies, energy management in high-tech facilities, cost-benefit assessments of building commissioning, and development of off-grid LED lighting systems for the developing world (for which he won the AEE Energy Innovaton of the Year award in 2006). He currently leads LBNL's Action-Oriented Benchmarking project, which is the subject of this article. Email: Emills@lbl.gov; Phone: (510) 486-6784. 
Norman J. Bourassa is the Team Lead for the Public Interest Energy Research (PIER) Buildings Program at the California Energy Commission. Previously, he worked for the Commercial Building Systems Group at Lawrence Berkeley National Laboratory (LBNL) and prior to that as an energy analyst with energy engineering consulting firms. Mr. Bourassa has degrees in Architecture from the University of California at Berkeley and Electronics Engineering Technology from the Northern Alberta Institute of Technology in Edmonton, Canada. Email: Njbouras@energy.state.ca.us; Phone: (916) 654-4581.

Martha Brook is a licensed mechanical engineer in the state of California. She has worked at the California Energy Commission for 18 years, where she has gained experience in long term energy demand forecasting, building energy efficiency standards (Standards), and research and development of energy efficient technologies for residential and commercial buildings. Ms. Brook is currently leading efforts to advance the Standards to deliver the climate change benefits of low carbon footprint buildings. Email: Mbrook@energy.state.ca.us; Phone: (916) 654-4086. 